\title{
PREHISTORIC TIME LINE
}

II,700-present years BP

I2,500-II, O०० years BP

I2,800-II, 500 years BP

I3,200-I2,500 years BP

I3,500-II,000 years BP

I4,700-I2,700 years BP

I6,800-I3,200 years BP

24,000-I6,800 years BP

24,500-I8,000 years BP

25,000-I3,000 years BP

IIO,০০o years ago to present

2.58 million years BP
Holocene

Post-Clovis fluted and unfluted (Late Paleo-American) culture

Younger Dryas

Clovis (Middle Paleo-American) culture

Nenana-Denali (Beringian Paleo-American) culture

Bølling interstadial

Proto-Clovis (Southeast Early Paleo-American) culture

Mid-Atlantic Early Paleo-American culture

French and Northern Spanish Solutrean culture

Last Glacial Maximum (LGM)

Last glacial period

Pliocene-Quaternary (current ice age) glaciation began 
This page intentionally left blank 